\title{
Implement Fama And French And Capital Asset Pricing Models In Saudi Arabia Stock Market
}

\author{
Abdulaziz Aldaarmi, Brunel University, London, UK \\ Maysam Abbod, Brunel University, London, UK \\ Hussein Salameh, Amman, Jordan
}

\begin{abstract}
This paper applies two of the famous asset pricing models in finance (Capital Assent Pricing model and Fama and French 1993 three factor model) in an emerging market with an Islamic Culture: Saudi Arabia Market (Tadwal), Generalized Methods of Moments and $t$ Test statistical techniques were used to find the coefficients and to compare between real and expected returns.The results show that Fama and French 1993 model has more explanatory power and do a better job in explaining the changes in stock returns than the CAPM, and those developed market models can be applicable in emerging markets like Saudi Arabia. CAPM model has a clear evidence for its applicability while Fama and French Model has a clear evidence for the market return but not a clear evidence for the size and book to market return. Finally the results show that we can predict the stock prices by using any of those two models which means that the Saudi Arabia Market is inefficient pricing Market.The modernity and low number of companies has a big effect on the results, in addition the strong purchasing power and strong cash availability.Finally we recommend to appply more modern pricing models at the micro and macro level and add variables consistent with the Islamic Culture of Saudi Arabia.
\end{abstract}

Keywords: Fama \& French (FF) Model; Stock Exchange Prediction; Capital Asset Pricing Model (CAPM)

\section{INTRODUCATION}

C $\mathrm{n}$ the middle of the previous century, Markowitz starts the finance science or the Modern Portfolio Theory by considering the return of an asset is adjusted to its risk at that time he got the Nobel for his contributions to the finance sciences, at the decade Modigliani and Muller publish their famous model about capital structure and corporate finance, it was in the fifties of the last century, ten years later in the sixties Markowitz student Sharp and three other scholars build the first asset pricing model it is the Capital Asset Pricing Model (CAPM) it describe how return is a linear adjusted to market risk beta and their model can applied for single asset or a portfolio but it is a single variable model. Then in the seventies of the last century Ross and Roll produced the Arbitrage Pricing Model APT it was a multivariate variable model for the return of the asset but it does illustrate what are those variables it may be Micro variables or Marco variables. In 1992, Fama and French (FF) identified their first model but their most famous model FF1993 was produced in 1993 which indicates that the asset returns are affected by three variables; market return,size return and book value to market value return. Finally Denial and Titman try to change the way of thinking in finance science by trying to turn the relationship between return and risk from risk factors to characteristics variables as they were trying to apply their model in markets around the world while the other scholars was trying to defend the old theories.

Saudi Arabia Exchange Market is an emerging Market It is a modern market in Saudi Arabia which has special features compaired to other exchanges Market around the world due to the Islamic Sharia which does not allow debt and interest. This makes it very difficult to apply known models for an emerging market like Saudi Arabia Market. In addition there are no taxes in Saudi Arabia because it a rich country,However, there is an Islamic Shara'a Zakat $(2.5 \%$ tax)on assets but not profit. 
Therefore, the problem of this research is to develop a model of an emerging stock market in Saudi Arabia which has special features due to its Islam religio,culture and tradition. To check if this market can be modeled, the CAPM and Fama and French three factor 1993 pricing models are applied to check which one is more appropriate to use. In Addition, this study argues the efficiency of Saudi Arabia Stock Exchange Market through comparing the real return with the returns prediced using CAPM and FF.

The importance of this research is to investigate the applicability of Fama and French (1993) three stock market factor model (size, book-to-market and market return) to Saudi Arabia; It is the first study that uses the same approach of Fama and French in measuring the dependent and independent variables. It will add evidence as to which of these risk factors affect the stock return.

According to the problem the following objectives are introduced:

- $\quad$ Specify a model that may predict the stock return in in Saudi Arabia Stock Exchange (Tadwal) by applying the factor of CAPM model, the three factors of FF model at the micro level.

- $\quad$ Compare the CAPM and FF real returns and with each other.

- $\quad$ Check if the predicting power of stock return can be improved .

This paper starts with the introduction, the second section introduces the literature review, the methodology is illustrated in the third section, while the forth section presents the results, finally, the fifth section presents the conclusion.

\section{LITERATURE REVIEW}

CAPM is one of the oldest and most conventional models used by various researchers to explain the cross sectional variation in stock market behaviour. This model is proposed by Sharpe (1964) and Lintner (1965) in their separate studies. The basic underlying assumption of capital asset pricing model is its linear function of a security's returns and relative risk of the market. A major implication of this model is that relative risk of the security is alone sufficient to explain the variability of its expected returns at all.

The model proposed by Fama and French $(1992,1993)$ is a modified version of this capital asset pricing model which assumes that cross sectional variaion in the expected returns of a security is a function of three factors: market risk, size of firm and its book to market ratio. Many academic researchers and economists have applied the FF models to the US and non-US equity market and concluded that, in emerging economies, the retuns on individual stocks are a decreasing fucntion of its size and increasing function of book to market ratio (Barry, Goldreyer, Lockwood, \& Rodriguez, 2002; Drew \& Veeraraghavan, 2001; Fama \& French, 1998).

Fama and French (1992) used two variables together to check the effect of the firms size and the value of the book to the market equity ratio to see how it impact the variation by using the cross section in average returns on the stock of the various material which is kept in the different firms as inventory. They have used the values of the $\beta$ for the variables of relative risk of security while other value of variables of price to earnings ratios. On the other hand, statistical analysis are made to check the effect of the variations in $\beta$, which are not related to the firm size and the association among market value of the $\beta$, it is found that the average return on these variables are found flat, when the value of the $\beta$ is just used as just explanatory variable.

Fama and French (1993) also applied their model along with two additional risk and return factors which may forecast and explain the possible variation in stock and bonds returns. The additional factors included in Fama and French three factor model are maturity and default risk of bonds market related. It is found by the results that stock market related variables like book to market and firm size successfully forecasted the returns variations in stock / equity portfolio. However, this Fama and French three factor model is successful in capturing the bond returns variation except only for low graded firms which have higher default risk. The final conclusion is that five factors, among those two are in addition to Fama and French three factor model or four are in addition to traditional capital asset pricing model, are essential in explaining variation in capital market returns and forecasting the capital market behavior. 
Later on, Fama (1998) stated that market efficiency depends upon the survival of different challenges based on the literature of various authors on long term return basis on the long term unique methods. These results were consistent with the hypothesis related to the efficiency and found that such results are unique and traced rarely in the literature due to uncertainty. Such reactions are found that clear information regarding over reaction is common. Fama found that there is total difference in the market efficiency in long term return unique patterns during under reaction events and as well as after events occur and he suggested that these are common results when discussed with respect to the behavior of the financial decisions for long period of the time as this is not true for the short term analysis on the firms investing patterns. The logic behind this is traced that during short term analysis, financial behavior cannot be treated in efficient way to get the results. Fama concluded that the methodology is changed then it can the results mostly in long term anomalies in capital markets trends that they tends to not appear properly due to reasonable change in the tools and techniques.

Further, $\mathrm{Hu}$ (2007) aruged that cost of the capital can be measured and estimated using various models as authentic source of estimation while there is common practice of estimation using the proxy of the premium factors which is found as the best practice of the previous historical studies. The study suggested a unique methodology for the estimation of the premium factors and has utilized various types of variables from business cycle. Trade strategy is used based on the sample results and concluded that the results defeated maximum previous estimation where lot of researchers have used general practices of the FF in developing economies. This study described that FF model found to be much better as compare to the CAPM where the results are interpreted in short run. While in long run model of asset-pricing in which researchers used estimation method found to be good in the performance perspectives of the firms in corporate sector of the developing economy. At the end it is recommended that for the estimation of the capital budgeting decisions in the corporate sector for short term planning Fama and French three factor model is one of the best method in business organizations.

Al-Zubi and Salameh (2009) have stated that capital asset pricing model helps all the countries in the world to enhance the savings of the firms and accept the challenges in the rivalry of firms in the corporate sector of the economies. The main purpose of their study is to specifically analyze and predict the return on the stock for industrial firms at Amman Stock Exchange. The main objective is to implement this model in the developed economy so that it can be verified and analyzed the cross sectional variations on the returns of the stock in the firms relevant to the industrial sector in Amman Stock Exchange. The study has used new technique and method of Generalized Methods of Moments by regressing these two model and their out put as results indicated that form FF model just two to three factors showed variation which were found to be common as cross section variations in the return of the stock comparatively better than capital asset pricing model CAPM.

China, as one of the major emerging economies, have also provided support for these conventional forecasting models. In the Shanghai and Shenzhen stock market, random walk hypotheseis is applcable (Liu, Song, \& Romilly, 1997), whereas a link between returns and lagged interests rates have also found in foreign markets (Su \& Fleisher, 1998). Drew et al. (2003) found that both the firm related factors of Fama and French model (book to market ratio and firm size) have a negative impact on stock price variations, however many other have found a positive sign between stock price and book to market ratio. In this regard, Wang and Di Iorio (2007) used the data set of 1994-2002 and concluded that beta is not an important predictor of stock returns; however, other two factors of FF model have significant explanatory power in cross sectional variation of stock returns. In addition, Wong et al. (2006) also found similar findings with Fama and French model by adding two other variables of average returns in preceeding six months and floating equity. Moreover, Chen et al. (2007) provided evidence on data from 1998-2007 that there is non-linera inverted U-shaped relationship exists between stock returns and book to market ratio for smaller firms.

Homsud et al. (2009) indicated the importance of FF model in the stock exchange of Thailand for five years from 2002 to 2007. The data of the 421 firms from developed economy of the Thailand and divided that data into six major groups and these groups as follows: Big size and high book to market value portfolio (BH), Big size and medium book to market value portfolio (BM), Big size and low book to market value portfolio (BL), Small size and high book to market value portfolio (SH), Small size and medium book to market value portfolio (SM), and Small size and low book to market value portfolio (SL). Big (B) and Small (S) taken as mean the mean size impact by measuring from the trends of the capitalization of the market of all companies in this study where they traced that 
high $(\mathrm{H})$, medium $(\mathrm{M})$ and low $(\mathrm{L})$ values have significant impact on the measurement from book to the market values of the firms in the developing economy of the Thailand. They traced that their research is able to adds two significant variables of firms specific factors the firms size and book to the market value ratios on the base of the capital asset pricing model by following the FF model's efficiency of the explanation and induced the risk factor and return on the assets in the Thailand stock exchange in BH, SH, BM, SL groups in mixed economy of the Thailand. It was concluded that FF model verified the variations explaining risk factor in the form of the returns of the stock which found to be better option as compare to the traditional model of the capital asset pricing model in fourth groups (SH, BH, BM, SL).

Along with this, Hamid et al. (2012) investigated and evaluated the efficiency of the FF using the variables asset of pricing and one other variable which is expected returns on the portfolio for various corporate stock in financial corporate sector in the mixed economy of Pakistan by taking the data of various firms from Karachi stock exchange. In their research they used the various six firms having portfolios in their corporate sector by using multivariate regression analysis on the base of the size and one other variable book value to market value. they used the monthly data from the financial sectors i.e. banks from developing economy of Pakistan from 2006 to 2010 up to January to December for the duration of the five years. Results indicated that majority of the firms in Pakistan which are using the FF have lot of the variations in returns.

Similarly, Bhatnagar and Ramlogan (2012) stated that the work done by the FF in various time periods helped the firms for the real use of the CAPM theorem and it contained the capability to explained the returns on the stock. This study used premium values for the calculation of the CAPM model used in the United State of America. Their work provided special perspective out of the sample from the previous work of FF using the multiple regressions for the comparison of the performance and evaluation of CAPM done in the developed economy of the United Kingdom.

Recently, Eraslan (2013) checked validity of FF model by taking the data from Istanbul Stock Exchange on the base of the monthly data from the period of the 2003 to 2010. Using firm size, it was found that firms having large size have more excess of expected return on average as compare to the small firms where both small and large firms both have portfolios in their corporate structure and policies. In general routine, firms which have low values of the book to market ratios in portfolio management have much better performance than those firms which have higher value of the book to market ratios. Further, it is reported that there is strong effect of the factor of risk on the portfolio of small firms and firms have large size do not have variation of portfolios and medium size firms have same impact at Istanbul Stock Exchange. The book to market ratio factor is found to have significant impact on the portfolios of the firms having high book to market in the perspectives of the portfolio management.

Finally, Shaker \& Elgiziry (2014) compared the applicability of five alternatives of asset pricing models in Egyptian stock market the CAPM, Fama-French three factor model, the Cahart four factor model, liquidityaugmented four factor model, and the five factor model (liquidity and momentum-augmented Fama-French three factor model. The sample is split into six portfolios sorted on size and book-to market ratio. The results based on GRS (1989) test show evidence that Fama-French model is the best and reject the other models. From their side, Shams, Abshari, Kordlouie, Naghshineh \& Gholipour (2014) studied the effect of information quality by regarding liquidity risk, and by regarding risk of market on non-ordinary return at Fama-French three model factor in Tehran Stock Exchange. The results show the influence of (SMB) and (HML) of the Fama-French three model factor was eliminated. In addition corporate properties and market are considered as market risk variables and liquidity risk. Also, results show that model is acceptable. At the end, Khalafalla (2014) investigated the validity of the capital asset pricing model CAPM, the arbitrage pricing theory APT, and the three factor model of Fama and French at Khartoum Stock Exchange KSE. Results showed that volatility computed via TARCH indicates the impact of the bad news on the conditional is twice as good news; in addition to the preference of generalized least squares over covariate (fixed effects) model as an estimation technique. Results are against the CAPM because the CAPM's prediction that the intercept should equal zero has not been attained, and its main assumption that the security market is efficient is violated. The APT showed no reaction to news from macroeconomic variables. Nevertheless, APT out-performed Fama-French model and CAPM. 


\section{METHODLOGY}

\subsection{Introduction}

The CAPM and FF models in Saudi Arabia Exchange (Tadwal) are applied to using the same FF methodology they measure the variables to check if those models can be applied in this emerging market. Finally, we comparisons between the measured returns according to those models with real variables and with each other were implemented.

\subsection{Data Description}

The period of this study extended from January 2007 to December 2011, using monthly stock prices for corporations listed in Saudi Arabia Stock Exchange (SASE). The source of all the data used in this study is the website of the Saudi Arabia Stock Exchange (http://www.tadawul.com.sa/). The number of observations is 60 in the first part of the study to check the applicability of those models. In the second part of the study, is to divide the data into two parts. The first one contains the first 48 observations, which represent the training period from 2007 to 2010, while the last 12 observations (twelve months in 2011) represent the test period.

\subsection{Describing, Forming and Measuring the Variables}

\subsubsection{Monthly Return}

The monthly return is the function of the price of the stock in the current month and the price of the stock in the previous month and can be represented in the following equation:

$$
\mathrm{R}_{\mathrm{ti}}=\left(\mathrm{P}_{\mathrm{ti}}-\mathrm{P}_{\mathrm{ti}-1}\right) / \mathrm{P}_{\mathrm{ti}-1}
$$

\subsubsection{Forming the Dependent Variables Portfolios}

All the companies of Saudi Arabia Stock Exchange are considered in this study and the $50 \%$ breakpoint for size at year $t$ is calculated. The sample stock on two size groups (B \& S) is placed on the breakpoint. B is used for big and S was used for small group. Two breakpoints, one at at 30\%, and the other at 70\%, for book-to-market at year t-1 for both groups are calculated. The sample companies are placed into three book-to-market groups for each size group. Big size and high book to market value portfolio $(\mathrm{B} / \mathrm{H})$ denotes the above $50 \%$ breakpoint for size and above $70 \%$ breakpoint, Big size and medium book to market value portfolio (B/M) denotes the above 50\% breakpoint for size and between 30\% and 70\% breakpoints for book-to-market, Big size and low book to market value portfolio (B/L) denotes above 50\% breakpoint for size and below $30 \%$ breakpoint for book-to-market, Small size and low book to market value portfolio (S/L) denotes below $50 \%$ breakpoint for size and below $30 \%$ breakpoint for book-to-market, Small size and medium book to market value portfolio (S/M) denotes below $50 \%$ breakpoint for size and between 30\% and 70\% breakpoints for book-to-market, and Small size and high book to market value portfolio $(\mathrm{S} / \mathrm{H})$ denotes below $50 \%$ breakpoint for size and above $70 \%$ for book-to-market. Hence, six valueweighted portfolios are formed $(\mathrm{B} / \mathrm{H}, \mathrm{B} / \mathrm{M}, \mathrm{B} / \mathrm{L}, \mathrm{S} / \mathrm{H}, \mathrm{S} / \mathrm{M}, \mathrm{S} / \mathrm{L})$ in the study period by adopting the FF methodology, but by applying Scientist Tim Loughran methodology in constructing the varied number of firms in each of the six portfolios as shown in table1due to the small number of companies in the Saudi Arabia Stock Exchange.

Table 1: Portfolio Partitioning

\begin{tabular}{cccc}
\hline \multirow{2}{*}{ SIZE } & \multicolumn{3}{c}{ BOOK TO MARKET } \\
\cline { 2 - 4 } & Above 70\% & Between 70\%- 30\% & Below 30\% \\
\hline Above 50\% & Big / High $(\mathrm{B} / \mathrm{H})$ & Big / Medium $(\mathrm{B} / \mathrm{M})$ & Big / Low (B/L) \\
Below 50\% & Small / High $(\mathrm{S} / \mathrm{H})$ & Small / Medium $(\mathrm{S} / \mathrm{M})$ & Small / Low $(\mathrm{S} / \mathrm{L})$ \\
\hline
\end{tabular}




\subsubsection{Forming the Independent Factors Portfolios}

Similar technique is adopted for forming the independent factors portfolios. Breakpoints for book-tomarket are $30 \%$, whereas $70 \%$ and $50 \%$ breakpoint for size is considered. Hence the six value-weighted portfolios $\mathrm{S} / \mathrm{L}, \mathrm{S} / \mathrm{M}, \mathrm{S} / \mathrm{H}, \mathrm{B} / \mathrm{L}, \mathrm{B} / \mathrm{M}, \mathrm{B} / \mathrm{H}$, are formed with varied number of firms in each portfolio. The SMB portfolio return is the difference between the return on the portfolios of small stocks and the return on the portfolios of big stocks and calculated from these portfolio returns and are defined as $R_{\mathrm{SMB}}=\left(\mathrm{R}_{\mathrm{SL}}+\mathrm{R}_{\mathrm{SM}}+\mathrm{R}_{\mathrm{SH}}-\mathrm{R}_{\mathrm{BL}}-\mathrm{R}_{\mathrm{BM}}-\mathrm{R}_{\mathrm{BH}}\right) / 3$. The HML portfolio return is the difference between the return on the portfolios of high book-to-market stocks and the return on a portfolio of low-book-to-market stocks and are defined as $\mathrm{R}_{\mathrm{HML}}=\left(\mathrm{R}_{\mathrm{SH}}+\mathrm{R}_{\mathrm{BH}}-\mathrm{R}_{\mathrm{SL}}-\mathrm{R}_{\mathrm{BL}}\right) / 2$. Another value- weighted portfolio was created that contains all the firms in the portfolios and is denoted by Mkt.

\subsubsection{Equations}

The equation of CAPM model is given below:

$$
\mathrm{R}_{\mathrm{i}}-\mathrm{R}_{\mathrm{f}}=\alpha_{\mathrm{i}}+\beta_{\mathrm{i}}\left(\mathrm{R}_{\mathrm{M}}-\mathrm{R}_{\mathrm{f}}\right)+\varepsilon_{\mathrm{i}}
$$

The equation of the three factors model of Fama and French is:

$\mathrm{R}_{\mathrm{i}}-\mathrm{R}_{\mathrm{f}}=\alpha_{\mathrm{i}}+\beta_{\mathrm{i}}\left(\mathrm{R}_{\mathrm{m}}-\mathrm{R}_{\mathrm{f}}\right)+\gamma_{\mathrm{i}} \mathrm{R}_{\mathrm{smb}}+\delta_{\mathrm{i}} \mathrm{R}_{\mathrm{hml}}+\varepsilon_{\mathrm{i}}$

The dependent variable is $\mathrm{R}_{\mathrm{i}}-\mathrm{R}_{\mathrm{f}}$ : the weighted average excess return for all the companies in stock market for six portfolio( $R_{f}$ : risk free rate of return) which are the following: (1) $R_{H B}$, which is Portfolio return for companies that are high Book-to-Market level and big group; (2) $\mathrm{R}_{\mathrm{HS}}$, which is Portfolio return for companies that are high Book-toMarket level and small group; (3) $\mathrm{R}_{\mathrm{MB}}$, which is Portfolio return for companies that are medium Book-to-Market level and big group; (4) $\mathrm{R}_{\mathrm{MS}}$, which is Portfolio return for companies that are medium Book-to-Market level and small group; (5) $\mathrm{R}_{\mathrm{LB}}$, which is Portfolio return for companies that are low Book-to-Market level and big group and finally (6) $R_{L S}$, which is Portfolio return for companies that are low Book-to-Market level and small group. The independent variables include the following. (1) $R_{M}$ : the market return portfolio is a sum over or aggregate portfolio of all individual investors, lending and borrowing will cancel out. In other words, it equals the entire wealth of the state economy (Bodie et al, 2002). The methodology of Fama and French for $\left(\mathrm{R}_{\mathrm{m}}-\mathrm{R}_{\mathrm{f}}\right)$ is the weighted average return of all the stocks in the sample. (2) $\mathrm{R}_{\mathrm{SMB}}$ : one of first and famous anomalies was size effect, which emphasizes that small size stocks had higher risk adjusted return than the stocks of the big size stocks (Banz, 1981). The methodology of Fama and French for $R_{S M B}$ is explained by the difference between the return portfolios of small and big of stocks, by this equation: $\mathrm{R}_{\mathrm{SMB}}=\left(\mathrm{R}_{\mathrm{SL}}+\mathrm{R}_{\mathrm{SM}}+\mathrm{R}_{\mathrm{SH}}-\mathrm{R}_{\mathrm{BL}}-\mathrm{R}_{\mathrm{BM}}-\mathrm{R}_{\mathrm{BH}}\right) / 3$. (3) $\mathrm{R}_{\mathrm{HML}}$ : another famous anomaly was book-to-Market effect, which emphasizes that low market value stocks had poor prospects and must be penalized by higher risk adjusted return (Banz, 1981). The methodology of Fama and French, for $\mathrm{R}_{\mathrm{HML}}$ is explained by the difference between the return on the portfolios of high and low-book-to-market stocks, through this equation: $\mathrm{R}_{\mathrm{HML}}$ $=\left(\mathrm{R}_{\mathrm{SH}}+\mathrm{R}_{\mathrm{BH}}-\mathrm{R}_{\mathrm{SL}}-\mathrm{R}_{\mathrm{BL}}\right) / 2$.

\subsection{Hypothesizes}

For each of the following portfolios

- $\quad$ Big size and high book to market value portfolio. (B/H)

- $\quad$ Small size and high book to market value portfolio. $(\mathrm{S} / \mathrm{H})$

- $\quad$ Big size and medium book to market value portfolio. (B/M)

- $\quad$ Small size and medium book to market value portfolio. (S/M)

- $\quad$ Big size and low book to market value portfolio. (B/L)

- $\quad$ Small size and low book to market value portfolio. (S/L)

The following hypothesizes are tested using GMM Regressions Coefficients. 


\subsubsection{CAPM Model Hypothesis}

\section{$\underline{\text { Hypothesis No. } 1}$}

Ho: There is no significant effect for the market return on the portfolio return on each of the six above portfolios.

\subsubsection{Fama and French 1993 three factor Model Hypothesis}

\section{Hypothesis No. 1}

Ho: there is no significant effect for the market return on the portfolio return on each of the six above portfolios

\section{Hypothesis No. 2}

Ho: There is no significant effect for the small size portfolio return on the portfolio return on each of the six above portfolios.

\section{Hypothesis No. 3}

Ho: there is no significant effect for the book-to-book market portfolio return on the portfolio return on each of the six above portfolios.

\subsubsection{Comparison Hypothesizes}

\section{Hypothesis No. 1}

Ho: There is no significant forecasting accuracy difference between each of the six estimated by the Fama and French model and each of the six real portfolios return

\section{Hypothesis No. 2}

Ho: There is no significant forecasting accuracy difference between each of the six portfolios return estimated by the CAPM model and each of the six real portfolios return.

\section{Hypothesis No. 3}

Ho: There is no significant forecasting accuracy difference between each of the six portfolios return estimated by the CAPM model and each of the six portfolio return estimated by the Fama and French model.

\subsection{Statistical Techniques}

\subsubsection{Generalized Methods of Moments (GMM)}

Regression is used to test the FF model. This regression does not require information of the exact distribution of the disturbances. In fact, many common estimators in econometrics can be considered as special cases of GMM. For example, the ordinary least squares estimator can be viewed as a GMM estimator in case that each of the right-hand variables is uncorrelated with the residual. Time series (HAC) Generalized Methods of Moments estimate will be robust to heteroskedasticity and autocorrelation of unknown form.

\subsubsection{Paired Samples t-Test}

In most cases the variances and standard of two populations are not known. The only information usually available is the sample means, the sample variances, and the sample standard deviations. If the assumptions are made that the samples are randomly and independent drawn from populations that are normally distributed and that 
the population variances are equal, a pooled - variance t-Test can be used to determine whether there is a significant difference between the means of the two populations (Berenson et al., 2002).

\section{RESULTS}

In this study two regressions for the stock returns are examined: the first regression that uses market return $\mathrm{R}_{\mathrm{m}}$ to explain the stock market return. The second regression uses three factors: market return, SMB (which represents the returns for size) and HML (which represents the return for book-to-market) to explain the stock return.

\subsection{Part A: Applying the CAPM and Fama and French 1993 three factor models}

\subsubsection{CAPM Model}

In Table 2, $\mathrm{R}^{2}$ the explanation power is from 0.28 to 0.69 which means that the market return explains good part of the variation in stock return, but not all of it. This means that there are other variables to explain the dependent variable.

Table 2: $\mathrm{R}^{2}$ (The Explanation Power) Results

\begin{tabular}{ccc}
\hline R-Squared & CAPM Model & Fama and French Model \\
\hline RHB & 0.284 & 0.472 \\
RHS & 0.293 & 0.339 \\
RMB & 0.438 & 0.434 \\
RMS & 0.685 & 0.702 \\
RLB & 0.698 & 0.731 \\
RLS & 0.692 & 0.703 \\
\hline
\end{tabular}

Furthermore, Table 3 show that the null hypothesis can be rejected which implies there is no significant effect of the market return variable (independent variable) on the small and big portfolios return as the P-value is less than 1\% (1-confidence level (99\%). This implies that can be accepted the alternative hypothesis which indicates that there is positive significant effect for the market value on the stock return for the small and big portfolios. While the coefficients of the market return (independent variable) are 0.38 and 0.65 and 0.90 for the small portfolios. And the coefficients of the market return (independent variable) are 0.37 and 0.49 and 0.85 for the big portfolios.

Table 3: CAPM Model Coefficient

\begin{tabular}{ccc}
\hline CAPM Model & C (2) & Prob. \\
\hline RHB & 0.369 & 0.0045 \\
RHS & 0.380 & 0.0018 \\
RMB & 0.498 & 0.0000 \\
RMS & 0.646 & 0.0000 \\
RLB & 0.854 & 0.0000 \\
RLS & 0.909 & 0.0000 \\
\hline
\end{tabular}

\subsubsection{Fama and French Three Factor Model}

In table $2, \mathrm{R}^{2}$ is from 0.73 to 0.34 , which means that the three factor model explains more of the variations in stock return than the CAPM model, but not all of it. This means that there are other variables which explains the dependent variable.

Moreover, Table 4 shows that the null hypothesis can be rejected which implies that there is no significant effect of the market return variable (independent variable) on the big portfolios return as the P-value is less than $1 \%$ (1-confidence level (99\%). This implies that the alternative hypothesis can be accepted which indicates that there is positive significant effect for the market value on the stock return for the big portfolios. While the coefficients of the market return (independent variable) are 0.98 and 0.61 and 0.76 big portfolios. 
Furthermore, table 4 shows that the null hypothesis can be rejected which implies that there is no significant effect of the market return variable (independent variable) on the small portfolios return as the P-value is less than 1\% (1-confidence level (99\%). This implies that the alternative hypothesis can be accepted which indicates that there is positive significant effect for the market value on the stock return for the small portfolios. While the coefficients of the market return (independent variable) are 0.77 and 0.84 and 0.91 for the small portfolios.

Table 4: Fama and French 1993 model Three Coefficients

\begin{tabular}{ccccccc}
\hline FF Model & C (2) & P.P & C (3) & P.P & C (4) & P.P \\
\hline RHB & 0.982 & 0.0000 & -0.373 & 0.0014 & 0.770 & 0.0000 \\
RHS & 0.778 & 0.0000 & 0.191 & 0.0779 & 0.514 & 0.0018 \\
RMB & 0.612 & 0.0001 & 0.038 & 0.7612 & 0.171 & 0.1799 \\
RMS & 0.842 & 0.0000 & 0.172 & 0.0834 & 0.251 & 0.0159 \\
RLB & 03762 & 0.0000 & -0.256 & 0.0607 & -0.114 & 0.3511 \\
RLS & 0.912 & 0.0000 & 0.058 & 0.6123 & -0.019 & 0.8657 \\
\hline
\end{tabular}

This means that the market return significantly affects the stock return in the six portfolios when regressed with the other two factors.

Table 4, shows the SMB size factor, the coefficients for big size high $\mathrm{B} / \mathrm{H}$, portfolio is significantly different than zero at 1 percent significant level but the coefficient for small size high $\mathrm{S} / \mathrm{H}$ and small size Medium $\mathrm{S} / \mathrm{M}$ and big size low $\mathrm{B} / \mathrm{L}$ portfolios are significantly different than zero at 10 percent significant, finally coefficients of big size Medium B/M, small size Low S/L portfolios are not significantly different than zero. The coefficients are positive for all the portfolios except the big size high $\mathrm{B} / \mathrm{H}$ and big size low $\mathrm{B} / \mathrm{L}$ portfolio it's coefficient sign is negative.

For the SMB size factor; Table 4 show that the null hypothesis can be rejected which implies that there is no significant effect of the SMB size variable (independent variable) on the for big size high $\mathrm{B} / \mathrm{H}$ portfolio returns as the P-value is less than 1\% (1-confidence level (99\%). This implies that the alternative hypothesis can be accepted which indicates that there is negative significant effect for the SMB size on the big size high $\mathrm{B} / \mathrm{H}$ portfolio return for the small portfolios.

Furthermore, Table 4 showed that for the SMB size factor the null hypothesis can be rejected which implies that there is no significant effect of the SMB size variable (independent variable) on the for small size high $\mathrm{S} / \mathrm{H}$ and small size Medium S/M and big size low $\mathrm{B} / \mathrm{L}$ portfolios returns as the $\mathrm{P}$-value is less than $10 \%$ (1-confidence level (90\%). This implies that the alternative hypothesis can be accepted which indicates that there is positive significant effect for the SMB size on the for small size high S/H and small size Medium S/M portfolios return and there is negative significant effect for the SMB size on big size low B/L portfolio return. Moreover, Table 4 show that for the SMB size factor, the null hypothesis cannot be rejected which implies that there is no significant effect of the SMB size variable (independent variable) on the big size Medium B/M, and small size Low S/L portfolios returns as the P-value is more than 10\% (1-confidence level (90\%). This implies that there is no significant effect for the SMB size on the big size Medium B/M, and small size Low S/L portfolios returns. The coefficients are positive for all the portfolios except the big size high $\mathrm{B} / \mathrm{H}$ and a big size low $\mathrm{B} / \mathrm{L}$ portfolio it's coefficient sign is negative.

For HML book-to-market factor, Table 4 show that the null hypothesis can be rejected which implies that there is no significant effect of the HML book-to-market variable (independent variable) on the big size high B/H and small size high $\mathrm{S} / \mathrm{H}$ portfolios returns as the $\mathrm{P}$-value is less than 1\% (1-confidence level (99\%). This implies that the alternative hypothesis can be accepted which indicates that there is positive significant effect for the HML bookto-market on the big size high $\mathrm{B} / \mathrm{H}$ and small size high $\mathrm{S} / \mathrm{H}$ portfolios return.

Furthermore, Table 4 show that for the HML book-to-market factor, the null hypothesis can be rejected which implies that there is no significant effect of the HML book-to-market variable (independent variable) on the for small size medium S/M portfolio returns as the P-value is less than 5\% (1-confidence level (95\%). This implies that the alternative hypothesis can be accepted which indicates that there is positive significant effect for the HML book-to-market on the small size medium S/M portfolio. 
Finally, Table 4 show that for the HML book-to-market factor, the null hypothesis cannot be rejected which implies that there is no significant effect of the HML book-to-market variable (independent variable) on the big size medium $\mathrm{B} / \mathrm{M}$ and big size low $\mathrm{B} / \mathrm{L}$ and small size low $\mathrm{S} / \mathrm{L}$ portfolios return as the $\mathrm{P}$-value is more than $10 \%$ (1confidence level (90\%). This implies that there is no significant effect for the HML book-to-market factor on the big size medium $\mathrm{B} / \mathrm{M}$ and big size low $\mathrm{B} / \mathrm{L}$ and small size low $\mathrm{S} / \mathrm{L}$ portfolios return. So there is no absolute evidence that this variable affects the stock return.

Adding SMB and HML to the regression has an interesting effect on the market $\beta$ s for stocks. It collapses the $\beta \mathrm{s}$ for stocks toward 1.0, low $\beta \mathrm{s}$ move up and high $\beta \mathrm{s}$ move down toward one. This behaviour is due to correlation between market and SMB or HML.

\subsubsection{The Cross-Section of Stock Return}

The intercept in the time series regression of returns should be indistinguishable from zero. Intercepts close to zero say that the regressions that use market return, SMB and HML to absorb common time series variation in returns do a good job in explaining the cross section of average stock returns. The result in Table 5 shows that some of the intercepts when regress three factor model are closer to zero than the intercepts for CAPM for three portfolios but not with a clear evidence because not all of them which means that using the three factor model market return, SMB and HML to absorb common time-series variation in returns does a better job in explaining the cross-section of average stocks returns.

Table 5: CAPM and Fama and French 1993 Intercepts

\begin{tabular}{lcccc}
\hline C (1) & CAPM Model & Prob. & FF Model & Prob. \\
\hline RHB & 0.008081 & 0.8126 & 0.016209 & 0.5077 \\
RHS & 0.025829 & 0.4867 & 0.004754 & 0.8853 \\
RBM & 0.006519 & 0.8166 & 0.001554 & 0.9522 \\
RMS & 0.009791 & 0.6062 & -0.001987 & 0.9101 \\
RLB & 0.007420 & 0.7615 & 0.017826 & 0.4280 \\
RLS & 0.002758 & 0.9154 & 0.002692 & 0.9182 \\
\hline
\end{tabular}

4.2 Part B: The Study Compares Between Forecasting Accuracy for the CAPM Model and Fama and French model using both GMM Regression and Real Returns of the Portfolios

\subsubsection{Measuring the Coefficients from the GMM Regression Results}

The CAPM model is tested first for 48 observations by conducting the Generalized Method of Moments (GMM) regression (Time Series Heteroskedasticity Autocorrelation (HAC)), to find the intercept and the coefficient for the six portfolios.

The equation for the CAPM model:

$$
\mathrm{R}_{\mathrm{i}}-\mathrm{R}_{\mathrm{f}}=\alpha_{\mathrm{i}}+\beta_{\mathrm{i}}\left(\mathrm{R}_{\mathrm{M}}-\mathrm{R}_{\mathrm{f}}\right)
$$

The results present in Table 6 shows the following:

- $\quad$ The intercept and the coefficient of big size and high book to market $\mathrm{B} / \mathrm{H}$ value portfolio.

$$
\mathrm{R}_{\mathrm{HB}}=0.0204+0.5755 \mathrm{R}_{\mathrm{M}}
$$

- $\quad$ The intercept and the coefficient of small size and high book to market $\mathrm{S} / \mathrm{H}$ value portfolio.

$$
\mathrm{R}_{\mathrm{HS}}=0.0185+0.4617 \mathrm{R}_{\mathrm{M}}
$$

- $\quad$ The intercept and the coefficient of big size and medium book to market $\mathrm{B} / \mathrm{M}$ value portfolio.

$\mathrm{R}_{\mathrm{MB}}=-0.0108+0.5683 \mathrm{R}_{\mathrm{M}}$

- $\quad$ The intercept and the coefficient of small size and medium book to market S/M value portfolio.

$$
\mathrm{R}_{\mathrm{MS}}=0.0081+0.7085 \mathrm{R}_{\mathrm{M}}
$$


- $\quad$ The intercept and the coefficient of big size and low book to market $\mathrm{B} / \mathrm{L}$ value portfolio.

$$
\mathrm{R}_{\mathrm{LB}}=0.0148+0.9054 \mathrm{R}_{\mathrm{M}}
$$

- $\quad$ The intercept and the coefficient of small size and low book to market value portfolio.

$$
\mathrm{R}_{\mathrm{LS}}=0.0044+0.9405 \mathrm{R}_{\mathrm{M}}
$$

\begin{tabular}{|c|c|c|c|c|c|}
\hline & Model & & $\begin{array}{c}\text { Intercept \& } \\
\text { Coefficient } \beta\end{array}$ & T Value & P Value \\
\hline \multirow{2}{*}{1} & \multirow{2}{*}{$\mathrm{RHB}=\mathrm{C}(1)+\mathrm{C}(2) * \mathrm{RM}$} & Intercept & 0.0204 & 0.549 & 0.585 \\
\hline & & Coefficients $\beta$ & 0.5755 & 4.040 & 0.000 \\
\hline \multirow{2}{*}{2} & \multirow{2}{*}{$\mathrm{RHS}=\mathrm{C}(1)+\mathrm{C}(2) * \mathrm{RM}$} & Intercept & 0.0185 & 0.482 & 0.638 \\
\hline & & Coefficients $\beta$ & 0.4617 & 3.467 & 0.001 \\
\hline \multirow{2}{*}{3} & \multirow{2}{*}{$\mathrm{RMB}=\mathrm{C}(1)+\mathrm{C}(2) * \mathrm{RM}$} & Intercept & -0.0108 & -0.411 & 0.682 \\
\hline & & Coefficients $\beta$ & 0.5683 & 5.044 & 0.000 \\
\hline \multirow{2}{*}{4} & \multirow{2}{*}{$\mathrm{RMS}=\mathrm{C}(1)+\mathrm{C}(2) * \mathrm{RM}$} & Intercept & 0.0081 & 0.356 & 0.723 \\
\hline & & Coefficients $\beta$ & 0.7085 & 10.851 & 0.000 \\
\hline \multirow{2}{*}{5} & \multirow{2}{*}{$\mathrm{RLB}=\mathrm{C}(1)+\mathrm{C}(2) * \mathrm{RM}$} & Intercept & 0.0148 & 0.573 & 0.569 \\
\hline & & Coefficients $\beta$ & 0.9054 & 9.823 & 0.000 \\
\hline \multirow{2}{*}{6} & \multirow{2}{*}{$\mathrm{RLS}=\mathrm{C}(1)+\mathrm{C}(2) * \mathrm{RM}$} & Intercept & 0.0044 & 0.169 & 0.865 \\
\hline & & Coefficients $\beta$ & 0.9405 & 9.325 & 0.000 \\
\hline
\end{tabular}

Table 6: CAPM Model 48 Observation Regression Six Portfolios Coefficient

The FF model is tested for the 48 observations by conducting the GMM regression to find the intercept and the coefficients for the four portfolios

The equation of the Fama and French three factor model is:

$$
\mathrm{R}_{\mathrm{i}}-\mathrm{R}_{\mathrm{f}}=\alpha_{\mathrm{i}}+\beta_{\mathrm{i}}\left(\mathrm{R}_{\mathrm{M}}-\mathrm{R}_{\mathrm{f}}\right)+\gamma_{\mathrm{i}} \mathrm{R}_{\mathrm{SMB}}+\delta_{\mathrm{i}} \mathrm{R}_{\mathrm{HML}}+\varepsilon_{\mathrm{i}}
$$

Table No 7 show the coefficients and t value and $\mathrm{p}$ value for the six portfolios tested according to FF which presents the following:

- $\quad$ The intercept and the coefficients of big size and high book to market $\mathrm{B} / \mathrm{H}$ value portfolio.

$$
\mathrm{R}_{\mathrm{HB}}=0.0246+0.9893 \mathrm{R}_{\mathrm{M}}-0.3447 \mathrm{R}_{\mathrm{SMB}}+0.8091 \mathrm{R}_{\mathrm{HML}}
$$

- $\quad$ The intercept and the coefficients of small size and high book to market $\mathrm{S} / \mathrm{H}$ value portfolio.

$$
\mathrm{R}_{\mathrm{H}}=-0.0093+0.8362 \mathrm{R}_{\mathrm{M}}+0.2037 \mathrm{R}_{\mathrm{SMB}}+0.496 \mathrm{R}_{\mathrm{HML}}
$$

- $\quad$ The intercept and the coefficients of big size and medium book to market $\mathrm{B} / \mathrm{M}$ value portfolio.

$$
\mathrm{R}_{\mathrm{MB}}=-0.0067+0.6084 \mathrm{R}_{\mathrm{M}}+0.0589 \mathrm{R}_{\mathrm{SMB}}+0.0329 \mathrm{R}_{\mathrm{HML}}
$$

- $\quad$ The intercept and the coefficients of small size and medium book to market value portfolio.

$$
\mathrm{R}_{\mathrm{MS}}=-0.0016+0.8507 \mathrm{R}_{\mathrm{M}}+0.1937 \mathrm{R}_{\mathrm{SMB}}+0.1831 \mathrm{R}_{\mathrm{HML}}
$$

- $\quad$ The intercept and the coefficients of big size and low book to market value portfolio.

$$
\mathrm{R}_{\mathrm{LB}}=0.0215+0.7927 \mathrm{R}_{\mathrm{M}}-0.1448 \mathrm{R}_{\mathrm{SMB}}-0.1441 \mathrm{R}_{\mathrm{HML}}
$$

- The intercept and the coefficients of small size and low book to market value portfolio.

$$
\mathrm{R}_{\mathrm{LS}}=-0.0034+0.9689 \mathrm{R}_{\mathrm{M}}+0.147 \mathrm{R}_{\mathrm{SMB}}-0.1058 \mathrm{R}_{\mathrm{HML}}
$$


Table 7: Tama and French 1993 Model 48 Observation Regression Six Portfolios Coefficient

\begin{tabular}{|c|c|c|c|c|c|}
\hline & Model & & $\begin{array}{c}\text { Intercept \& } \\
\text { Coefficients } \beta\end{array}$ & T Value & P Value \\
\hline \multirow{4}{*}{1} & \multirow{4}{*}{$\mathrm{RHB}=\mathrm{C}(1)+\mathrm{C}(2) * \mathrm{RM}+\mathrm{C}(3) * \mathrm{R}_{\mathrm{SMB}}+\mathrm{C}(4) * \mathrm{R}_{\mathrm{HML}}$} & Intercept & 0.0246 & 0.840 & 0.405 \\
\hline & & $\mathrm{RM} \beta$ & 0.9893 & 8.312 & 0.000 \\
\hline & & RSMB $\beta$ & -0.3447 & 2.667 & 0.010 \\
\hline & & RHML $\beta$ & 0.8091 & 4.852 & 0.000 \\
\hline \multirow{4}{*}{2} & \multirow{4}{*}{$\mathrm{RHS}=\mathrm{C}(1)+\mathrm{C}(2) * \mathrm{RM}+\mathrm{C}(3) * \mathrm{RSMB}+\mathrm{C}(4) * \mathrm{RHML}$} & Intercept & -0.0093 & -0.281 & 0.779 \\
\hline & & $\mathrm{RM} \beta$ & 0.8362 & 4.974 & 0.000 \\
\hline & & RSMB $\beta$ & 0.2037 & 2.801 & 0.007 \\
\hline & & RHML $\beta$ & 0.496 & 3.091 & 0.003 \\
\hline \multirow{4}{*}{3} & \multirow{4}{*}{$\mathrm{RMB}=\mathrm{C}(1)+\mathrm{C}(2) * \mathrm{RM}+\mathrm{C}(3) * \mathrm{RSMB}+\mathrm{C}(4) * \mathrm{RHML}$} & Intercept & -0.0067 & -0.251 & 0.802 \\
\hline & & $\mathrm{RM} \beta$ & 0.6084 & 4.289 & 0.000 \\
\hline & & RSMB $\beta$ & 0.0589 & 0.591 & 0.557 \\
\hline & & RHML $\beta$ & 0.0329 & 0.246 & 0.806 \\
\hline \multirow{4}{*}{4} & \multirow{4}{*}{$\mathrm{RMS}=\mathrm{C}(1)+\mathrm{C}(2) * \mathrm{RM}+\mathrm{C}(3) * \mathrm{RSMB}+\mathrm{C}(4) * \mathrm{RHML}$} & Intercept & -0.0016 & -0.077 & 0.938 \\
\hline & & $\mathrm{RM} \beta$ & 0.8507 & 8.325 & 0.000 \\
\hline & & RSMB $\beta$ & 0.1937 & 1.773 & 0.083 \\
\hline & & RHML $\beta$ & 0.1831 & 1.504 & 0.139 \\
\hline \multirow{4}{*}{5} & \multirow{4}{*}{$\mathrm{RLB}=\mathrm{C}(1)+\mathrm{C}(2) * \mathrm{RM}+\mathrm{C}(3) * \mathrm{RSMB}+\mathrm{C}(4) * \mathrm{RHML}$} & Intercept & 0.0215 & 0.871 & 0.338 \\
\hline & & $\mathrm{RM} \beta$ & 0.7927 & 6.016 & 0.000 \\
\hline & & RSMB $\beta$ & -0.1448 & -1.033 & 0.307 \\
\hline & & RHML $\beta$ & -0.1441 & -1.034 & 0.306 \\
\hline \multirow{4}{*}{6} & \multirow{4}{*}{$\mathrm{RLS}=\mathrm{C}(1)+\mathrm{C}(2) * \mathrm{RM}+\mathrm{C}(3) * \mathrm{RSMB}+\mathrm{C}(4) * \mathrm{RHML}$} & Intercept & 0.0034 & -0.123 & 0.902 \\
\hline & & $\mathrm{RM} \beta$ & 0.9689 & 7.894 & 0.000 \\
\hline & & RSMB $\beta$ & 0.147 & 1.360 & 0.180 \\
\hline & & RHML $\beta$ & -0.1058 & -0.680 & 0.500 \\
\hline
\end{tabular}

\subsubsection{Paired Sample t-Test Results}

Table 8 demonstrates comparison results between forecast accuracy measures according to CAPM model and Fama and the French three factor model using GMM Regression, and a comparison results between forecast curacy measures according to CAPM model using GMM regression and the real returns of the six portfolios. And a comparison results between forecast accuracy measures according to Fama and French model using to GMM regression and the real returns of the six portfolios.

Hypothesis No 1

The result in Table 8 shows that we can't reject the null hypothesis: There is no significant forecasting accuracy difference between each of the six portfolios return estimated by the CAPM model (using GMM Regressions Coefficients) and each of the six portfolios return estimated by the Fama and French model using (GMM Regressions Coefficients) because the P-Value is more than 10\% significant level for six portfolios.

\section{Hypothesis No 2}

The result in Table 8 shows that the null hypothesis cannot be rejected: There is no significant forecasting accuracy difference between each of the six portfolios return estimated by the CAPM model using (GMM) and each of the real six portfolios returns because the P-Value is more than $10 \%$ significant level for the six portfolios.

\section{$\underline{\text { Hypothesis No } 3}$}

The result in Table 8 shows that the null hypothesis cannot be rejected: There is no significant forecasting accuracy difference between each of the six portfolios return estimated by the FF model using (GMM Regressions Coefficients) and each of the six real portfolios returns because the P-Value is more than $10 \%$ significant level for the six portfolios. 
Table 8: t-Test Comparison Results

\begin{tabular}{|c|c|c|c|c|}
\hline $\begin{array}{l}\text { Hypothesis } \\
\text { No. }\end{array}$ & Compare Between & T Value & P Value & $\begin{array}{l}\text { Reject or } \\
\text { Accept Ho }\end{array}$ \\
\hline 1 & $\begin{array}{l}\text { GMM CAPM \& GMM FF Model (Big Size High Book to } \\
\text { Market) Portfolio }\end{array}$ & -0.002 & 0.999 & Accept \\
\hline 1 & $\begin{array}{l}\text { GMM CAPM \&GMM FF Model (Big Size Medium Book to } \\
\text { Market) Portfolio }\end{array}$ & -1.518 & 0.157 & Accept \\
\hline 1 & $\begin{array}{l}\text { GMM CAPM \&GMM FF Model (Big Size low Book to Market) } \\
\text { Portfolio }\end{array}$ & 1.039 & 0.321 & Accept \\
\hline 1 & $\begin{array}{l}\text { GMM CAPM \&GMM FF Model (Small Size High Book to } \\
\text { Market) Portfolio }\end{array}$ & 0.150 & 0.884 & Accept \\
\hline 1 & $\begin{array}{l}\text { GMM CAPM \&GMM FF Model (Small Size Medium Book to } \\
\text { Market) Portfolio }\end{array}$ & -0.464 & 0.651 & Accept \\
\hline 1 & $\begin{array}{l}\text { GMM CAPM \&GMM FF Model (Small Size low Book to } \\
\text { Market) Portfolio }\end{array}$ & 0.088 & 0.931 & Accept \\
\hline 2 & $\begin{array}{l}\text { GMM CAPM \& Real Portfolios Returns (Big Size High Book to } \\
\text { Market) Portfolio }\end{array}$ & 0.432 & 0.674 & Accept \\
\hline 2 & $\begin{array}{l}\text { GMM CAPM \& Real Portfolios Returns (Big Size Medium Book } \\
\text { to Market) Portfolio }\end{array}$ & 0.769 & 0.458 & Accept \\
\hline 2 & $\begin{array}{l}\text { GMM CAPM \& Real Portfolios Returns (Big Size low Book to } \\
\text { Market) Portfolio }\end{array}$ & 1.039 & 0.321 & Accept \\
\hline 2 & $\begin{array}{l}\text { GMM CAPM \& Real Portfolios Returns (Small Size High Book } \\
\text { to Market) Portfolio }\end{array}$ & 0.956 & 0.360 & Accept \\
\hline 2 & $\begin{array}{l}\text { GMM CAPM \& Real Portfolios Returns (Small Size Medium } \\
\text { Book to Market) Portfolio }\end{array}$ & -0.466 & 0.650 & Accept \\
\hline 2 & $\begin{array}{l}\text { GMM CAPM \& Real Portfolios Returns } 1 \text { (Small Size low Book } \\
\text { to Market) Portfolio }\end{array}$ & 0.746 & 0.471 & Accept \\
\hline 3 & $\begin{array}{l}\text { GMM FF Model \& Real Portfolios Returns (Big Size High Book } \\
\text { to Market) Portfolio }\end{array}$ & 0.096 & 0.297 & Accept \\
\hline 3 & $\begin{array}{l}\text { GMM FF Model \& Real Portfolios Returns (Big Size Medium } \\
\text { Book to Market) Portfolio }\end{array}$ & 0.822 & 0.428 & Accept \\
\hline 3 & $\begin{array}{l}\text { GMM FF Model \& Real Portfolios Returns (Big Size low Book to } \\
\text { Market) Portfolio }\end{array}$ & 1.138 & 0.279 & Accept \\
\hline 3 & $\begin{array}{l}\text { GMM FF Model \& Real Portfolios Returns (Small Size High } \\
\text { Book to Market) Portfolio }\end{array}$ & 0.781 & 0.451 & Accept \\
\hline 3 & $\begin{array}{l}\text { GMM FF Model \& Real Portfolios Returns (Small Size Medium } \\
\text { Book to Market) Portfolio }\end{array}$ & -0.282 & 0.783 & Accept \\
\hline 3 & $\begin{array}{l}\text { GMM FF Model \& Real Portfolios Returns (Small Size low Book } \\
\text { to Market) Portfolio }\end{array}$ & 0.580 & 0.574 & Accept \\
\hline
\end{tabular}

\section{DISCUSSION}

Asset security pricing models is one of hottest research area in finance sciences in the developed markets, a lot of research is done and huge efforts of scholars are concentrated on this subject, the first, most famous and applicable model is CAPM which was introduced in the sixties of the last century by sharp and others, several models were tested but the one which add a value to the factors that affect asset prices is FF model (market return, size and book to market).

The results illustrate that for the CAPM model FF model explains good part of the variation in stock return, but not all of it which means that there are other variables to explain the dependent variable. But the FF model has more explanatory power than the CAPM. Also, the results show when applying the CAPM model for the six portfolios of the study that there is positive significant effect for the market value on the stock return for the small and big portfolios. 
The results of FF model show that there is positive significant effect for the market value on the stock return for the small and big portfolios. For the size effect two of the big size portfolio has a negative significant effect for the size factor (which consistent with the theory upon the sign of the effect) while one of the big size portfolios has insignificant effect, while for the small portfolio also two portfolios of the small size portfolios has a positive significant effect for the size factor (which inconsistent with the theory upon the sign of the effect). Finally for the book to market effect, one of the big size portfolio has a positive significant effect for the book to market factor (which consistent with the theory upon the sign of the effect) while two of the big size portfolios has insignificant effect, while for the small portfolio also two portfolios of the small size portfolios has a positive significant effect for the book to market factor (which inconsistent with the theory upon the sign of the effect) while one portfolio of the book to market effect.

In addition the results of the comparison show that 48 observations are used to find the coefficients of the independent variables for the two models and use those coefficients to expect the return of the six portfolios for each model then compare with the real returns we found that there is no significant difference between the real return of the six portfolios and the expected returns of the six portfolios according to the CAPM model and FF Model, also there is no significant difference between the expected return of the six portfolios according to the CAPM model and the expected returns of the six portfolios according to FF Model.

This Study presents that the models of the developed markets can be applied in emerging markets with special characteristics like Saudi Arabia, there is a clear evidence for the applicability of the CAPM model, it has a good explanatory power and do a good job in explaining the stock return that because any stock or portfolio is a part of the index portfolio or part of the whole stock portfolio in the market. The interesting result was that FF model show a better explanatory power than CAPM and do a better job in explaining the stock return also, even it has a clear evidence of the market return effect with a correct sign still it does not have a clear evidence for the size effect and its sign because that is one of the anomalies in the developed markets (due to the fact that those small size portfolios or stocks has not been studied very well for the analyst. The big size portfolios in the Saudi Arabia Market has a correct sign but not a clear evidence which means that this anomaly is exist in an emerging market like Saudi Arabia, but for the small portfolios if has not a clear evidence because two of three portfolios has significant effect but the positive sign clarify that the number of companies in the market is too small about 200 companies which affect the results. Finally for the book to market effect three of the six portfolios show that it has a significant positive sign while the other three portfolios has insignificant effect, therefore there is not a clear evidence of this factor which present that when the book to market value increase the risk increase so we ask for more return from it than the low book to market value, this can be clarify by the strong structure healthy of those Saudi Arabia market who's companies has strong cash deposits and high purchasing power. From the comparison side there is a predicting power in Saudi Arabia Market because it is a modern and emerging market because there is no difference between the real returns and expected returns upon the asset pricing models.

\section{CONCLUSIONS}

This study recommend that more models applicable in developed markets must be applied in Saudi Arabia Market but by adding new variables at the micro and macro level that say the story of the nature of the religious and culture. In addition the market efficiency of the Saudi Arabia Market must be tested deeply by applying the Efficient Market Hypothesis tests at the three forms to improve the confidence of the risk adjusted return reward investing background in front of speculating methodology. Finally it is recommended to overcome the low number of the companies of the Saudi Arabia market by developing a new technique to construct the portfolios.

\section{AUTHOR INFORMATION}

Abdulaziz Aldaarmi is a PhD student at Brunel University UK since 2011; he is at the stage of discussing his Dissertation. The title of his dissertation is "An electronic financial system adviser for investors with non-financial expertise's in Saudi Arabia" through his dissertation he used Artificial neural network ANN. His master is in economics from King Saud University 2008. He has one published article "A Data Model for Processing Financial Market and News Data in Electronic Financial System for Investors with Non- Financial Expertise: The Case of Saudi Arabia" Finally, His researches interests cover several subjects, i.e. investment, portfolio management, financial markets). (Corresponding Author) 
Maysam Abbod is a Senior Lecturer in Intelligent Systems/Course Director for EEE programs at Brunel University London UK. He received his PhD in Control Engineering from University of Sheffield in 1992. He was with the Department of Automatic Control and Systems Engineering at the University of Sheffield as a research associate and senior research fellow (1993 to 2006). His main research interests are in Intelligent hybrid modeling and control of industrial manufacturing systems, Intelligent techniques for developing physical models of systems, Developments of advanced process modeling, optimization and control strategies, Data mining and data driven modeling techniques.

Hussein Mohammad Salameh Recently he is early retired in Jordan/Social Security since 1/2014, and was Associate Professor in Finance/Amman Arab University (1year), and was Manager of Accreditation and Quality Assurance Department (1 $1 \frac{1}{2}$ year), Acting Manger of Admission and Registration Department ( $1 / 2$ year) and Associate Professor (since 2011) in Finance/Arab Academy for Banking and Financial Sciences enrolled at the university since 2006, and teaches as a visiting Lecturer for three semesters in MBA program (part time)/ Arab Academy, Damascus branch, Syria. His researches have been accepted in several leading academic journal (covering several subjects, i.e. corporate finance, investment, portfolio management, financial markets).

\section{REFERENCES}

Al-Zubi, K. A., Salameh, H. M. (2009). Tests of the Fama and French Three Factor Model in Jordan. Sasin Journal of Management, 15(1), 4-25.

Banz, R., (1981) "The relationship between return and market value of common stocks," Journal of Financial Economics, vol. 9, pp. 13-18.

Barry, B., Goldreyer, E., Lockwood, L., \& Rodriguez, M.(2002). Robustness of size and value effects in emerging equity markets, 1985-2000. Emerging Markets Review, 3(1), 1-30.

Bhatnagar, C. S., \& Ramlogan, R.(2012). The capital asset pricing model versus the three factor model: A United Kingdom Perspective. International Journal of Business and Social Research, 2(1), 51-65.

Bodie, Z., Kane, A., and Marcus, A., "Investments," McGraw-Hill, 2008, pp. 30-35.

Chen, J., Kan, K. L., \& Anderson, H. (2007). Size, book/market ratio and risk factor returns: evidence from China A-share market. Managerial Finance, 33(8), 574-594.

Drew, M. E., Naughton, T., \& Veeraraghavan, M. (2003). Firm size, book-to-market equity and security returns: Evidence from the Shanghai Stock Exchange. Australian Journal of Management, 28(2), 119-139.

Drew, M., \& Veeraraghavan, M. (2001). Explaining the cross-section of stock returns in the Asian region. International Quarterly Journal of Finance, 205-222.

Eraslan, V. (2013). Fama and French Three-Factor Model: Evidence from Istanbul Stock Exchange. Business and Economics Research Journal, 4(2), 11-22.

Fama, E. F. (1998). Market efficiency, long-term returns, and behavioral finance. Journal of financial economics, 49(3), 283-306.

Fama, E. F., \& French, K. R. (1992). The cross- section of expected stock returns. The journal of finance, 47(2), 427-465.

Fama, E. F., \& French, K. R. (1993). Common risk factors in the returns on stocks and bonds. Journal of financial economics, 33(1), 3-56.

Fama, E. F., \& French, K. R.(1998). Value versus growth: The international evidence. The journal of finance, 53(6), 1975-1999.

Hamid, Z., Hanif, A., Malook, S. S., \& Wasimullah.(2012). Fama and French three factor model: Empirical evidence from financial market of Pakistan. African Journal of Business Management, 6(8), 2945-2950.

Homsud, N., Wasunsakul, J., Phuangnark, S., \& Joongpong, J.(2009). A study of Fama and French three factors model and capital asset pricing model in the Stock exchange of Thailand. International Research Journal of Finance and Economics, 25, 31-40.

Hu, O. (2007). Applicability of the Fama-French three-factor model in forecasting portfolio returns. Journal of financial research, 30(1), 111-127.

Khalafalla, A.,(2014), "P0rtfolfio Formation; Empirical Evidence from Khartoum Stock Exchange” International Journal of Social Sciences and Entrepreneurship, Issue 9, Vol.1.

Lintner, J. (1965). The valuation of risk assets and the selection of risky investments in stock portfolios and capital budgets. The review of economics and statistics, 13-37. 
Liu, X., Song, H., \& Romilly, P.(1997). Are Chinese stock markets efficient? A cointegration and causality analysis. Applied Economics Letters, 4(8), 511-515.

Saudi Stock Exchange Tadawal. http://www.tadawul.com.sa/, Mar. 2008, [Feb. 16, 2013].

Shaker, M., \& Elgiziry, K.,(2014), "Comparisons of Asset Pricing Models in the Egyptian Stock Market", Accounting and Finance Research, No.4, Vol.3.

Shams, M., Abshari, L., Kordlouie, H., Naghshineh, N., \& Gholipour, M.,(2014), "Studying the Relationship between Liquidity Risk and Market Risk with Non-Ordinary Return at Fama-French Three Factor Model at Tehran Stock Exchange", International Business Research, No.2, Vol.7.

Sharpe, W. F. (1964). Capital asset prices: A theory of market equilibrium under conditions of risk. The journal of finance, 19(3), 425-442.

Su, D., \& Fleisher, B. M. (1998). Risk, return and regulation in Chinese stock markets. Journal of Economics and Business, 50(3), 239-256.

Wang, X. L., Shi, K., \& Fan, H. X.(2006). Psychological mechanisms of investors in Chinese Stock Markets. Journal of Economic Psychology, 27(6), 762-780.

Wang, Y., \& Di Iorio, A.(2007). The cross section of expected stock returns in the Chinese A-share market. Global Finance Journal, 17(3), 335-349. 